\title{
Subpopulations of cells from bronchoalveolar lavage can predict prognosis in sarcoidosis
}

\author{
To the Editor:
}

Sarcoidosis is characterised by an accumulation of $\mathrm{CD}^{+} \mathrm{T}$-cells in the lungs and an increased bronchoalveolar lavage fluid (BALF) $\mathrm{CD} 4 / \mathrm{CD} 8$ ratio (>3.5) [1]. In sarcoidosis, an expansion of BALF $\mathrm{CD}^{+} \mathrm{T}$-cells expressing the T-cell receptor $\mathrm{V} \alpha 2.3$ has been associated with good prognosis and with specific HLA-alleles, i.e. HLA-DRB1 ${ }^{\star} 0301$ and HLA-DRB3 ${ }^{\star} 0101$ (which is often carried together with HLA-DRB1 $\left.{ }^{\star} 13\right)$. HLA-DRB ${ }^{\star} 03$ and HLA-DRB $3^{\star} 0101$ molecules show similarities in the region important for antigen presentation and both may therefore be capable of presenting identical antigens to the lung T-cells [2]. Furthermore, an expansion defined as $>10.5 \% \mathrm{CD}^{+} \mathrm{V} \alpha 2.3^{+}$BALF T-cells is commonly seen in patients with Löfgren's syndrome [3], which is characterised by an acute onset with bilateral ankle arthritis and/or erythema nodosum, bilateral hilar lymphadenopathy and, in some cases, with parenchymal infiltrates and usually fever [4]. We have previously shown that very high expansions of $\mathrm{CD}^{+} \mathrm{V} \alpha 2.3^{+} \mathrm{T}$-cells are associated with Löfgren's syndrome and a disease duration $<2$ years [3]. However, not all patients with an expansion of $\mathrm{CD}^{+} \mathrm{V} \alpha 2.3^{+} \mathrm{T}$-cells have Löfgren's syndrome and resolving disease. In this much enlarged study on a HLA-typed sarcoidosis cohort, we aimed at investigating the clinical characteristics of patients with an expansion of $\mathrm{CD} 4^{+} \mathrm{V} \alpha 2.3^{+} \mathrm{T}$-cells in BALF and to analyse if the degree of expansion may predict the prognosis of sarcoidosis.

In a registry of sarcoidosis patients ( $\mathrm{n}=661$, including 252 with Löfgren's syndrome), all investigated with bronchoscopy and BAL for diagnostic purposes and HLA-typed and followed for at least 2 years, 248 subjects were identified with BALF $\mathrm{CD} 4^{+} \mathrm{V} \alpha 2.3^{+} \mathrm{T}$-cells expansions. An expansion was defined as three times the median percentage of $\mathrm{V} \alpha 2.3^{+} \mathrm{CD} 4^{+} \mathrm{T}$ cells in peripheral blood of healthy subjects, as previously described $(3 \times 3.5 \%)$ [3]. Disease activity was evaluated 2 years after disease onset, considering presence of symptoms (e.g. cough, fatigue, dyspnoea, fever), serum-ACE activity, spirometry values and chest radiographic findings. Patients without any pathological findings were regarded to have a resolving disease.

We focused on patients with $\mathrm{V} \alpha 2.3^{+} \mathrm{CD}^{+}$T-cell expansions, out of which $73 \%$ had classical Löfgren's syndrome (table 1). They were all judged to have active disease at the time for bronchoscopy. The percentage of $\mathrm{V} \alpha 2.3^{+} \mathrm{CD}^{+} \mathrm{T}$-cells in BALF is known to be normalised when the patients recover [5]. All patients were without immunosuppressive treatment at the time for bronchoscopy. After 2 years follow-up very few patients with Löfgren's syndrome, but some more with non-Löfgren's syndrome, had been treated with immunosuppressants. The sarcoidosis diagnosis was made through typical clinical and radiographic manifestations, findings at bronchoscopy with BAL including an elevated CD4/CD8-ratio (>3.5) and/or positive biopsies, in accordance with the criteria of the World Association of Sarcoidosis and other Granulomatous Disorders [6]. Chest radiographs were evaluated as previously described [7]. Written informed consent was obtained from all subjects, and approval was granted from the regional ethical review board.

Bronchoscopy with BAL was carried out as described before [8]. Surface markers expressed on T-cells were analysed using flow cytometry and all patients were HLA-typed as previously described $[9,10]$.

Statistical analyses were performed with Graph Pad Prism 6 (GraphPad Software Inc., San Diego, CA, USA). When comparing several groups such as differences between HLA-DRB1* alleles, $\mathrm{p}<0.003(\mathrm{p}<0.05$ divided

@ERSpublications

The higher the proportion of a T-cell subset $\left(\mathrm{CD}^{+} \mathrm{V \alpha 2} .3^{+} \mathrm{T}\right.$-cells $)$ in bronchoalveolar lavage fluid of sarcoidosis patients, the better the prognosis and therefore it may be used as an additional prognostic tool http://bit.ly/2Mta0Cs

Cite this article as: Darlington P, Kullberg S, Eklund A, et al. Subpopulations of cells from bronchoalveolar lavage can predict prognosis in sarcoidosis. Eur Respir J 2020; 55: 1901450 [https://doi. org/10.1183/13993003.01450-2019]. 


\begin{tabular}{|c|c|c|}
\hline & LS & Non-LS \\
\hline Subjects & 180 & 68 \\
\hline Male/female & $111 / 69$ & $41 / 27$ \\
\hline Age years ${ }^{\#}$ & $37(21-62)$ & $45(26-72)$ \\
\hline Radiographic stage $0 / \mathrm{I} / \mathrm{II} / \mathrm{III} / \mathrm{IV} \#$ & $0 / 123 / 57 / 0 / 0$ & $4 / 16 / 36 / 8 / 4$ \\
\hline Resolving/non-resolving ${ }^{\#}$ & $166 / 14$ & $25 / 43$ \\
\hline CD4/CD8 ratio* & $9.8(0.9-56.8)$ & $7.1(1.2-24.0)$ \\
\hline$\%$ Va2.3 BALF cells ${ }^{\#}$ & $28.4(11.0-50.0)$ & $17.8(11.4-44.3)$ \\
\hline HLA-DRB $1 * 03^{+} I^{-}$ & $155 / 25$ & $36 / 32$ \\
\hline \multicolumn{3}{|l|}{ Vo2.3 BALF cells \% } \\
\hline HLA-DRB $1 * 03^{+\#}$ & 29.9 & 20.5 \\
\hline HLA-DRB $1 * 03^{-* *}$ & 19.8 & 14.8 \\
\hline \multicolumn{3}{|l|}{ Patients recovered \% } \\
\hline HLA-DRB $1 * 03^{+\#}$ & 94 & 39 \\
\hline HLA-DRB $1 * 03^{-* *}$ & 80 & 34 \\
\hline
\end{tabular}

by 13) was regarded as significant after Bonferroni correction for the number of alleles $(\mathrm{n}=13)$, and otherwise $\mathrm{p}<0.05$ was regarded as significant.

High percentages of $\mathrm{CD}^{+} \mathrm{V} \alpha 2.3^{+} \mathrm{T}$-cells (i.e. $\mathrm{V} \alpha 2.3^{+} \mathrm{CD} 4^{+} \mathrm{T}$-cells $>10.5 \%$ in BALF) associated with a resolving disease, as $77 \%$ (191 out of 248) of these patients resolved within 2 years compared with $28 \%$ (114 out of 413$)$ of patients with normal levels $(p<0.0001)$. The proportion of patients who recovered increased gradually with the increasing proportion of $\mathrm{CD}^{+} \mathrm{V} \alpha 2.3^{+} \mathrm{T}$-cells in BALF, for example in patients with $0-5 \%$ of $\mathrm{CD}^{+} \mathrm{V} \alpha 2.3^{+} \mathrm{T}$-cells $25 \%$ had resolving disease; in the range $11-15 \%$, $44 \%$ resolved and when there were $21-25 \% \mathrm{~V} \alpha 2.3^{+}$T-cells, $82 \%$ resolved. If $>30 \%, 95 \%$ resolved.

Patients with Löfgren's syndrome had higher proportion of $\mathrm{CD}^{+} \mathrm{V} \alpha 2.3^{+}$T-cells in BALF compared to non-Löfgren's syndrome patients and were also younger at disease onset (table 1). Furthermore, patients with Löfgren's syndrome who carried the HLA-DRB1 ${ }^{\star} 03$ allele had a higher median $\mathrm{CD} 4^{+} \mathrm{V} \alpha 2.3^{+} \mathrm{T}$-cell proportion in BALF compared to HLA-DRB1*03- with Löfgren's syndrome $(p<0.0001)$. Among the HLA-DRB1 ${ }^{\star} 03^{-}$patients, HLA-DRB1 ${ }^{\star} 13$ was carried by $88 \%$ of the patients with Löfgren's syndrome and by $63 \%$ with non-Löfgren's syndrome.

In this study, we chose to focus on patients with an expansion of $\mathrm{CD} 4^{+} \mathrm{V} \alpha 2.3^{+} \mathrm{T}$-cells in BALF. The highest proportion of $\mathrm{CD}^{+} \mathrm{V} \alpha 2.3^{+} \mathrm{T}$-cells in the present study was seen in Löfgren's syndrome patients who were HLA-DRB $1^{*} 03^{+}$. The non-LS group was characterised by a less pronounced expansion of $\mathrm{V} \alpha 2.3^{+} \mathrm{T}$-cells and disease onset at a higher age. That older patients have less favourable outcome has been shown in another cohort [11].

Our hypothesis is that patients with expansion of $\mathrm{CD}^{+} \mathrm{V} \alpha 2.3^{+} \mathrm{T}$-cells (i.e. V $\alpha 2.3^{+} \mathrm{CD} 4^{+} \mathrm{T}$-cells $>10.5 \%$ in BALF) may have a more effective eradication of a presumed disease-promoting antigen. An influx of $\mathrm{CD}^{+} \mathrm{V} \alpha 2.3^{+} \mathrm{T}$-cells to the lungs may then explain the concomitant pronounced CD4/CD8 ratio. We have in a previously study showed that the BALF CD4 ${ }^{+} \mathrm{V} \alpha 2.3^{+} \mathrm{T}$-cells express significantly reduced levels of FOXP3 versus $\mathrm{CD}^{+} \mathrm{V} \alpha 2.3^{-}$T-cells [12], suggesting the $\mathrm{CD} 4^{+} \mathrm{V} \alpha 2.3^{+}$T-cells function as effector cells rather than regulatory cells, in line with a hypothetically more efficient elimination of a hypothetical sarcoidosis-antigen by such T-cells.

The clinical presentation, i.e. Löfgren's syndrome or non-Löfgren's syndrome, may reflect an altered immune and inflammatory reaction influenced by different exposures or genetic differences, which also include other inflammatory genes (e.g. tumour necrosis factor gene variants linked to HLA-DRB $1^{\star} 03$ variants). A hypothetical antigen might itself also have properties that may influence the inflammatory reaction, e.g. by inducing auto-immune reactions due to similarities of the inciting antigen and some self-structures or by preferentially stimulating a T helper (Th) 1-, Th 2- or a Th 17-dominant response.

In conclusion, the findings in this study indicate that the more pronounced the expansion of $\mathrm{CD} 4^{+} \mathrm{V} \alpha 2.3^{+}$ $\mathrm{T}$-cells in the BAL fluid is, the better the prognosis. The usefulness of $\mathrm{Va} 2.3^{+} \mathrm{T}$-cells as a prognostic 
marker is described here for a Scandinavian cohort. Whether they may be of clinical interest in other populations needs to be analysed in future studies.

Pernilla Darlington $\odot^{1}$, Susanna Kullberg ${ }^{2}$, Anders Eklund ${ }^{2}$ and Johan Grunewald ${ }^{2}$

${ }^{1}$ Respiratory Medicine Division, Dept of Clinical Science and Education, Södersjukhuset and Karolinska Institutet, Stockholm, Sweden. ${ }^{2}$ Respiratory Medicine Division, Dept of Medicine Solna and Center for Molecular Medicine (CMM), Karolinska University Hospital and Karolinska Institutet, Stockholm, Sweden.

Correspondence: Pernilla Darlington, Respiratory Medicine Division, Dept of Medicine, Södersjukhuset, Stockholm, Sweden. E-mail: pernilla.lidin-darlington@sll.se

Received: 10 June 2019 | Accepted after revision: 14 Aug 2019

Author contributions: P. Darlington designed the study, characterised patients, summarised data and drafted the manuscript. S. Kullberg characterised patients, interpreted data and helped writing the manuscript. A. Eklund and J. Grunewald co-designed the study and characterised patients, interpreted data and helped writing the manuscript. All authors read and approved the final manuscript.

Conflict of interest: None declared.

Support statement: This work was supported by the Swedish Heart-Lung Foundation, the King Gustaf V's and Queen Victoria's Freemasons' Foundation, the Swedish Research Council and Karolinska Institutet. Support was also given through the regional agreement on medical training and clinical research (ALF) between Stockholm County Council and Karolinska Institutet. None of the funding sources had any influence on the production of this manuscript. Funding information for this article has been deposited with the Crossref Funder Registry.

\section{References}

1 Costabel U. CD4/CD8 ratios in bronchoalveolar lavage fluid: of value for diagnosing sarcoidosis? Eur Respir J 1997; 10: 2699-2700.

2 Grunewald J, Wahlstrom J, Berlin M, et al. Lung restricted T cell receptor AV2S3+CD4+T cell expansions in sarcoidosis patients with a shared HLA-DR beta chain conformation. Thorax 2002; 57: 348-352.

3 Grunewald J, Berlin M, Olerup O, et al. Lung T-helper cells expressing T-cell receptor AV2S3 associate with clinical-features of pulmonary sarcoidosis. Am J Respir Crit Care Med 2000; 161: 814-818.

4 Löfgren S. Erythema nodosum. Studies on etiology and pathogenesis in 185 adult cases. Acta Med Scand 1946: $1-197$.

5 Planck A, Eklund A, Grunewald J. Markers of activity in clinically recovered human leukocyte antigen-DR17-positive sarcoidosis patients. Eur Respir J 2003; 21: 52-57.

6 Hunninghake GW, Costabel U, Ando M, et al. Statement on sarcoidosis. Am J Respir Crit Care Med 1999; 160: 736-755.

7 Darlington P, Tallstedt L, Padyukov L, et al. HLA-DRB1* alleles and symptoms associated with Heerfordt's syndrome in sarcoidosis. Eur Respir J 2011; 38: 1151-1157.

8 Olsen HH, Grunewald J, Tornling G, et al. Bronchoalveolar lavage results are independent of season, age, gender and collection site. PLoS One 2012; 7: e43644.

9 Darlington P, Haugom-Olsen H, von Sivers K, et al. T-cell phenotypes in bronchoalveolar lavage fluid, blood and lymph nodes in pulmonary sarcoidosis - indication for an airborne antigen as the triggering factor in sarcoidosis. J Intern Med 2012; 272: 465-471.

10 Grunewald J, Brynedal B, Darlington P, et al. Different HLA-DRB1 allele distributions in distinct clinical subgroups of sarcoidosis patients. Respir Res 2010; 11: 25.

11 Rubio-Rivas M, Corbella X, Mañá J. Elderly sarcoidosis: a comparative study from a 42-year single-centre experience. Respir Med 2019; 152: 1-6.

12 Idali F, Wahlström J, Müller-Suur C, et al. Analysis of regulatory T cell associated forkhead box P3 expression in the lungs of patients with sarcoidosis. Clin Exp Immunol 2008; 152: 127-137. 